\title{
The Affective and Neural Correlates of Heroin versus Cocaine Use in Addiction Are Influenced by Environmental Setting But in Opposite Directions
}

\author{
(1) Silvana De Pirro, ${ }^{1,2,3}$ (Caspare Galati, ${ }^{4,5}$ Luigi Pizzamiglio, ${ }^{4,5}$ and $\mathbb{C}^{\circ}$ Aldo Badiani ${ }^{1,2,3}$ \\ ${ }^{1}$ Sussex Addiction Research and Intervention Centre (SARIC), School of Psychology, University of Sussex, Brighton, BN1 9QH, United Kingdom, ${ }^{2}$ Sussex \\ Neuroscience, University of Sussex, Brighton, BN1 9QH, United Kingdom, ${ }^{3}$ Department of Physiology and Pharmacology, Sapienza University of Rome, \\ 00185 Rome, Italy, ${ }^{4}$ Department of Psychology, Sapienza University of Rome, 00185 Rome, Italy, and ${ }^{5}$ Istituto di Ricovero e Cura a Carattere Scientifico, \\ Santa Lucia Foundation, 00142 Rome, Italy
}

Previous studies have shown that individuals with heroin and cocaine addiction prefer to use these drugs in distinct settings: mostly at home in the case of heroin and mostly outside the home in the case of cocaine. Here we investigated whether the context would modulate the affective and neural responses to these drugs in a similar way. First, we used a novel emotional task to assess the affective state produced by heroin or cocaine in different settings, based on the recollections of male and female drug users. Then we used fMRI to monitor neural activity during drug imagery (re-creating the setting of drug use) in male drug users. Consistent with our working hypothesis, the majority of participants reported a shift in the affective valence of heroin from mostly pleasant at home to mostly unpleasant outside the home $(p<0.0001)$. The opposite shift was observed for cocaine; that is, most participants who found cocaine pleasant outside the home found it unpleasant when taken at home $(p<0.0014)$. Furthermore, we found a double dissociation, as a function of drug and setting imagery, in BOLD signal changes in the left PFC and caudate, and bilaterally in the cerebellum (all $p$ values $<0.01$ ), suggesting that the fronto-striatal-cerebellar network is implicated in the contextualization of drug-induced affect. In summary, we report that the same setting can influence in opposite directions the affective and neural response to psychostimulants versus opiates in humans, adding to growing evidence of distinct substrates for the rewarding effects of these two drug classes.

Key words: addiction; context; emotion; fMRI; opiates; psychostimulants

Significance Statement

The rewarding effects of addictive drugs are often thought to depend on shared substrates. Yet, environmental influences can unmask striking differences between psychostimulants and opiates. Here we used emotional tasks and fMRI to explore the influence of setting on the response to heroin versus cocaine in individuals with addiction. Simply moving from one setting to another significantly decreased heroin pleasure but increased cocaine pleasure, and vice versa. Similar double dissociation was observed in the activity of the fronto-striatal-cerebellar network. These findings suggest that the effects of opiates and psychostimulants depend on dissociable psychological and neural substrates and that therapeutic approaches to addiction should take into account the peculiarities of different drug classes and the settings of drug use.

\section{Introduction}

Previous studies in individuals with substance use disorder (SUD) have shown that the context in which heroin and cocaine are used

\footnotetext{
Received Jan. 4, 2018; revised April 18, 2018; accepted April 25, 2018.

Author contributions: S.D.P., G.G., L.P., and A.B. designed research; S.D.P. performed research; S.D.P., G.G., and A.B. analyzed data; S.D., G.G., and A.B. wrote the paper.

This study was supported by Sapienza University of Rome Fondi di Ateneo to A.B. and G.G. and by the University of Sussex Strategic Development Fund to A.B. We thank Giovanni lavarone for help with the organization of the fMRI study; Massimo Barra, Ettore Rossi, and the staff of Villa Maraini, as well as the participants for their time and commitment; and Drs. Kent Berridge, Cecilia Guariglia, and Terry Robinson for insightful comments on an earlier version of the manuscript.
}

can influence their reinforcing effects in a substance-specific manner. When asked where they preferred using these drugs, they indicated distinct settings: heroin was used mostly at home, whereas cocaine was used mostly outside the home, regardless of route of administration and social context (Caprioli et al., 2009;

The authors declare no competing financial interests.

Correspondence should be addressed to either Dr. Aldo Badiani or Dr. Silvana De Pirro, School of Psychology, University of Sussex, Pevensey 1 Building, BN1 9RH, Brighton, United Kingdom, E-mail: aldo.badiani@sussex.ac.uk orS.DePirro@sussex.ac.uk.

DOI:10.1523/JNEUROSCI.0019-18.2018

Copyright $\odot 2018$ the authors $\quad 0270-6474 / 18 / 385182-14 \$ 15.00 / 0$ 
Badiani and Spagnolo, 2013). Intravenous self-administration experiments in the rat yielded similar findings. Rats residing in the self-administration chamber (which is also their home environment) tend to prefer heroin to cocaine, whereas rats that do not reside in the self-administration chamber tend to prefer cocaine to heroin (Caprioli et al., 2009). Many aspects of cocaine versus heroin reward appear to be modulated in opposite directions by the setting: drug intake (Caprioli et al., 2007b, 2008), motivation to work for the drug (Caprioli et al., 2007b, 2008; Celentano et al., 2009), drug discrimination (Paolone et al., 2004; Caprioli et al., 2007a), drug-induced ultrasonic vocalizations (Avvisati et al., 2016), and vulnerability to relapse (Montanari et al., 2015). The findings in the rat suggest that the results obtained in humans were not the trivial consequence of a conscious decision to take a sedative drug in a place where one can relax, and an activating drug where one can move around, but reflected fundamental and substance-specific influences of setting on the response to drugs. The question to be addressed here concerns whether such preferences may be due the fact that heroin and cocaine produce different affective states in different settings.

We have proposed that the overall rewarding effects of addictive drugs are the result of a complex interaction between their central and peripheral effects and the setting of drug use (Badiani, 2013). Cocaine, for example, produces a state of arousal by activating noradrenergic transmission both centrally and peripherally (Billman, 1995; Sofuoglu and Sewell, 2009; Maceira et al., 2014; Antoniazzi et al., 2017). A similar state of physiological arousal usually occurs when individuals are exposed to exciting, potentially dangerous contexts. Thus, when cocaine is taken at home, the exteroceptive information signaling a quiet environment might conflict with the interoceptive information signaling a state of arousal, resulting in a "mismatch" between exteroceptive and interoceptive information. The reverse line of reasoning applies to heroin, which depresses the CNS and acts in a complex manner in the periphery producing, among other effects, bradycardia (Haddad and Lasala, 1987; Thornhill et al., 1989; Nilsson et al., 2016). When heroin is taken outside the home, there is a mismatch between exteroceptive information requiring alertness and vigilance and interoceptive information signaling reduced arousal and relaxation. In summary, the setting of drug use provides an "ecological backdrop" against which the central and peripheral effects of drugs are appraised, and when a mismatch between exteroceptive and interoceptive information is detected, the rewarding effect of the drug is thwarted.

The first aim of our study was to test the hypothesis that the affective response to heroin and cocaine, as recollected by experienced drug users, would undergo opposite shifts as a function of the setting. In particular, we hypothesized that the positive affective valence of heroin would be greater at home than outside the home, and that the opposite would occur for cocaine.

Our second aim was to begin exploring the neural basis of drug-setting interactions using an emotional imagery task and fMRI. We expected to observe changes in BOLD signal in the regions of the memory retrieval network (Fletcher et al., 1995; Spaniol et al., 2009; Kuhl and Chun, 2014; Bonnici et al., 2016; Richter et al., 2016), and a double dissociation, as a function of drug and setting, in regions implicated in drug reward processing, such as the PFC and the striatum, (Volkow et al., 1999; Cox et al., 2009).

\section{Materials and Methods}

\section{Experiment 1}

Participants. Prospective participants with a diagnosis of heroin or cocaine use disorder (DSM-IV or DSM-5) were recruited during their daily visit at the Substance Misuse Services of Villa Maraini (Rome) and were then screened for the following inclusion criteria: (1) age between 18 and 68 years; (2) fixed residence at the time of regular drug use; (3) good understanding of Italian or English language; (4) no psychoses, or bipolar disorders, or major depressive disorder; (5) no current alcohol dependence (as indicated by a state of inebriation at the moment of recruitment or by treatment for alcohol abuse); and (6) no cognitive impairment or state of intoxication, such as to preclude informed consent or valid selfreport. Before the start of the study, the participants were informed about the structure of the study and in particular that: (1) the questionnaires would focus on their current (or past) heroin and/or cocaine use; (2) the data thus collected would remain anonymous and confidential; and (3) they were free to withdraw from the study at any time they wished. After having briefed about the study, the participants provided informed consent. Procedures and methods were in accordance with the Declaration of Helsinki and were approved by the University of Sussex Science and Technology Cross-Schools Research Ethics Committee. Participation in the study was voluntary, and no monetary or nonmonetary incentives were offered.

Fifty-three individuals (mean $\pm \mathrm{SD}$ age, $37.11 \pm 10.42$ years), who identified themselves as females (11) or males (42), participated in the experiment. The sample included 45 heroin and cocaine users, 7 cocaineonly users, and 1 heroin-only user. All of them had a long history of heroin (15.96 \pm 10.31 years) and/or cocaine (14.44 \pm 8.51 years) use. Table 1 summarizes the socio-demographic characteristics of the sample and basic information about drug use. The majority of the participants $(86.79 \%)$ had a fixed residence at the time of their enrolment in the study. However, it is important to point out that the information concerning the setting of drug use referred to periods in which the participants had a fixed residence.

Procedures. The emotional state induced by the drug was assessed using a graphic approach based on the Circumplex Model of Affect (Russell, 1980), illustrated in Figure $1 A$, which posits that all affective states arise from the interaction of two independent neurobiological systems: arousal (along high-low energy continuum) and valence (along a pleasuredispleasure continuum). Our aim was to develop a user-friendly, intuitive test that could be completed rapidly without relying on the cognitive processes required for the verbal description and interpretation of emotional states, which could have represented a confounding factor given the participants' negative feelings about their own addiction (Dearing et al., 2005; Luoma et al., 2012, 2013). Thus, we created the diagram illustrated in Figure $1 B$, representing a 2D space of emotional state with arousal on the vertical dimension and valence on the horizontal dimension. Emoticons and colors were added to increase the evocative power of the diagram (Nathanson et al., 2016; Kaye et al., 2017).

The interview took place (during the participants' daily visit for treatment) in a quiet medical room at the Substance Misuse Service Villa Maraini. Responses were collected by the interviewer and entered into the online survey host Survey-Gizmo (https://www.surveygizmo.com) using the offline mode.

At the start of the interview, anonymized demographic data were collected, and the diagram (Fig. $1 B$ ) was explained to the participants following the procedures described by Russell et al. (1989). The diagram was presented as a 2D spatial map of emotional states, with the center of the circle representing a neutral state (which is not positive or negative). Consequently, the participants could position themselves in one of the quadrants according to the following combination: (1) top-right yellow quadrant if the emotional state experienced was simultaneously pleasurable and arousing; (2) bottom-right green quadrant if the emotional state was simultaneously pleasurable and sedating; (3) bottom-left blue quadrant if the emotional state was simultaneously unpleasant and sedating; and (4) top-left red quadrant if the emotional state was simultaneously unpleasant and arousing.

The participants were instructed to recall a typical drug experience and to rate the affective state produced by heroin versus cocaine in two settings (at home vs outside the home). Before the interview, they were also instructed to exclude instances of combined heroin and cocaine use ("speedball").

For each combination of drug and setting, the participants were asked to choose the quadrant that best reflected the affective states experienced 
Table 1. Socio-demographic information and diagnostic characteristics of the study sample for Experiment $1(n=53)$

\begin{tabular}{|c|c|}
\hline Characteristic & Mean (SD) or $\%$ \\
\hline \multicolumn{2}{|l|}{ Drug use } \\
\hline Heroin and cocaine & $84.91 \%$ \\
\hline Heroin only & $1.89 \%$ \\
\hline Cocaine only & $13.21 \%$ \\
\hline Age (years) & $37.11(10.42)$ \\
\hline Sex/gender (females) & $21 \%$ \\
\hline Education (years) $^{a}$ & $11.21(3.47)$ \\
\hline \multicolumn{2}{|l|}{ Ethnicity } \\
\hline Caucasian & $88.68 \%$ \\
\hline Multiethnic & $7.55 \%$ \\
\hline Black/African & $1.89 \%$ \\
\hline Indian/Pakistani/Bangladeshi & $1.89 \%$ \\
\hline \multicolumn{2}{|l|}{ Employment status $^{a}$} \\
\hline Employed & $46.34 \%$ \\
\hline Retired/disability & $9.76 \%$ \\
\hline Controlled environment & $9.76 \%$ \\
\hline Unemployed & $34.15 \%$ \\
\hline Fixed residence & $86.79 \%$ \\
\hline \multicolumn{2}{|l|}{ Household } \\
\hline Family/partner & $82.61 \%$ \\
\hline Alone & $10.87 \%$ \\
\hline Flat mates & $6.52 \%$ \\
\hline Methadone program ${ }^{b}$ & $84.91 \%$ \\
\hline $\mathrm{mg} / \mathrm{d}$ & $55.91(57.24)$ \\
\hline Heroin & $n=46$ \\
\hline Years of use & $15.96(10.31)$ \\
\hline \multicolumn{2}{|l|}{ Main route of administration } \\
\hline Intravenous injection & $54.35 \%$ \\
\hline Inhalation (smoked) & $23.91 \%$ \\
\hline Insufflation (snorted) & $21.74 \%$ \\
\hline Cocaine & $n=52$ \\
\hline Years of use & $14.44(8.51)$ \\
\hline \multicolumn{2}{|l|}{ Main route of administration ${ }^{c}$} \\
\hline Intravenous injection & $26.00 \%$ \\
\hline Inhalation (smoked) & $26.00 \%$ \\
\hline Insufflation (snorted) & $48.00 \%$ \\
\hline
\end{tabular}

while under the influence of the drug. Because we expected that in some case the affective state experienced while under the effect of the drug could not be reduced to a single condition, no restriction was placed on the number of affective states that the participant could report for each combination of set and setting. In $82.7 \%$ of cases, the participants indicated a single quadrant, more rarely two quadrants (15.3\%) and only in $2 \%$ of cases they selected three or four quadrants. In $11.2 \%$ of cases, the selection of more than one quadrant resulted in a mixed valence (pleasant and unpleasant at the same time). That is, in $88.8 \%$ of cases, the valence was either entirely pleasant or entirely unpleasant.

Data analysis. Data were classified and analyzed to test two separate hypotheses. The main working hypothesis predicted a complete or partial shift in the affective valence of heroin and cocaine as a function of setting. Thus, the data were arranged in a $2 \times 2$ contingency table, and the McNemar's test was used to assess the difference between the two correlated proportions (McNemar, 1947). A more rigorous reading of the working hypothesis would require limiting the analysis to the individuals who experienced heroin-induced sedation in both settings and to those who experienced cocaine-induced activation in both settings. That is, all cases in which there was a discrepancy for the dimension "arousal" were excluded from this analysis. Also, this hypothesis was tested using the McNemar's test. Effect size was estimated by calculating odds ratios (ORs).

The second hypothesis, often surreptitiously incorporated in theoretical and experimental frameworks, is that all drugs produce "pleasure."
For each combination of drug and setting, we calculated the observed frequency of the following three categories: (1) pleasant (by combining the frequency of entries for quadrants "pleasant-arousing" and "pleasantsedating"), (2) unpleasant (by combining the frequency of entries for quadrants "unpleasant-arousing" and "unpleasant-sedating"), and (3) mixed valence (for all the instances in which both pleasant and unpleasant quadrants were selected). We used the one-sample Kolmogorov-Smirnov test (Massey, 1951) to assess the degree to which the observed frequencies differed from the expected frequencies based on the "pleasure" hypothesis (pleasant:mixed:unpleasant $=1: 0: 0)$. We also tested a "weak" version of the "pleasure" hypothesis in which the categories pleasant and mixed were combined (pleasant $/$ mixed:unpleasant $=1: 0$ ).

\section{Experiment 2}

Participants. Prospective participants (who did not overlap with the participants in Experiments 1) with a diagnosis of heroin or cocaine dependence (DSM-IV) were recruited during their daily visit at the Substance Misuse Services of Villa Maraini and were then screened for the following inclusion criteria: (1) age between 18 and 55 years; (2) heroin and/or cocaine use at least once a week in the past 12 months; (3) fixed residence; (4) no history of neurological disorder or head trauma with loss of consciousness exceeding $30 \mathrm{~min}$; (5) no other contraindication to MRI; (6) no psychoses, or bipolar disorders, or major depressive disorder; (7) no current alcohol dependence (as indicated by a state of inebriation at the moment of recruitment or by treatment for alcohol abuse); and (8) no cognitive impairment or state of intoxication, such as to preclude informed consent or valid self-report. Before the start of the study, the participants were informed about the structure of the study and in particular that: (1) they would undergo an imagery procedure during the fMRI scan; (2) the data thus collected would remain anonymous and confidential; and (3) they were free to withdraw from the study at any time they wished. After having been briefed about the study, the participants provided informed consent. Procedures and methods were in accordance with the Declaration of Helsinki and were approved by the Istituto di Ricovero e Cura a Carattere Scientifico, Santa Lucia Foundation Ethics Committee. The participants received a flat reimbursement of 30 euro for their time. Refreshments were provided during the prescanning and postscanning time

Twenty-five individuals were recruited initially. Two individuals were excluded because of their inability to focus on imagery during training and one because of signs of distress produced by the scanner noise. Two individuals were excluded before completing the scan because of claustrophobia. Finally, the fMRI data from 1 participant were excluded from further analysis because of technical problems during acquisition.

The sample that completed the study consisted of 20 male individuals (age $35.35 \pm 8.13$ years) with history of both heroin ( $13.20 \pm 6.29$ years) and cocaine (15.25 \pm 5.74 years) abuse. Demographic information is reported in Table 2.

Procedures: emotional imagery. We adapted an emotional imagery procedure based on previous work by Lang and colleagues (Lang, 1979; Lang et al., 1980) to ask the participants to imagine taking heroin and cocaine in two different real-world settings where they had previously used these drugs.

Script. The scripts for the imagery task were developed based on selfreports collected on occasion of previous studies (Caprioli et al., 2009; Badiani and Spagnolo, 2013) and of pilot interviews. Emotional imagery procedures are capable of eliciting a mental representation that is not simply a picture scanned with the "mind's eye" but a dynamic scenario based on real-life experience, involving high-level cognitive functions, such as perception, memory, emotion, and motor control (Rollins et al., 1992; Kosslyn et al., 2001; Owen et al., 2006; Berger and Ehrsson, 2014). Previous studies reported similar neural substrates for imagery and perception, demonstrating that it is possible to induce a subjective experience resembling an actual perceptual experience by using verbal instructions based on an appropriate script (Lang, 1979; Reddy et al., 2010; Cichy et al., 2012; Lee et al., 2012). In agreement with previous studies (Lang, 1979; Lang et al., 1980; Dougherty et al., 1999; Cuthbert et al., 2003; McTeague et al., 2009; Costa et al., 2010), each script was structured to include the following: (1) the instruction to create a mental 


\section{A Circumplex Model of Affect (Russel 1980)}

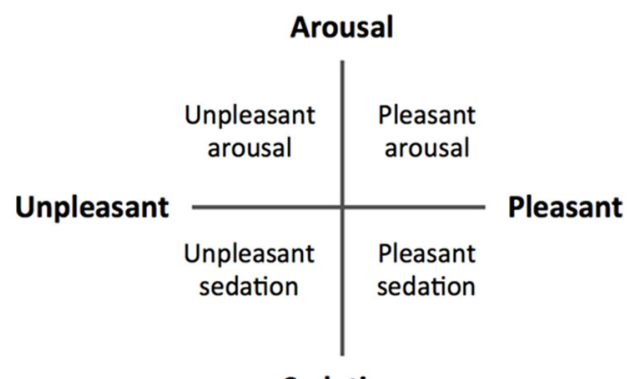

\section{B Graphic representation of affective states}

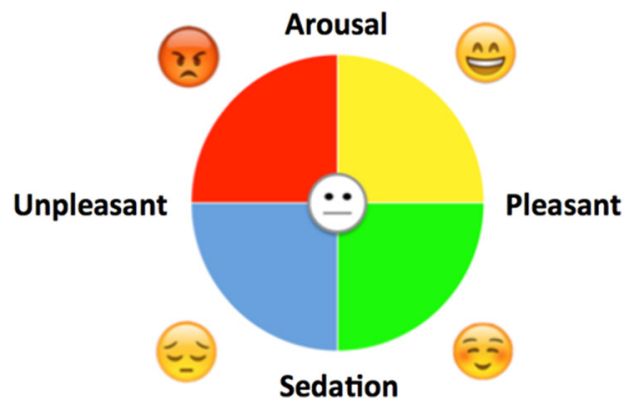

Figure 1. Assessment of affective states. $\boldsymbol{A}$, Graphic representation of the Circumplex Model of Affect (Russell, 1980). B, Bidimensional representation of affective states used in Experiment 1. This test was developed based on the Circumplex Model of Affect (left) by removing the labels indicating different levels for each dimension and by adding emoticons.

Table 2. Socio-demographic information, diagnostic characteristics and prescan data for Experiment $2(n=20)$

\begin{tabular}{|c|c|}
\hline Characteristic & Mean (SD) or \% \\
\hline Age (years) & $35.35(8.13)$ \\
\hline Education (years) & $13.60(3.31)$ \\
\hline Employed & $85 \%$ \\
\hline Handedness (left/ambidextrous/right) & $5 \% / 0 \% / 95 \%$ \\
\hline Methadone program & $95 \%$ \\
\hline $\mathrm{mg} / \mathrm{d}$ & $39.47(30.00)$ \\
\hline \multicolumn{2}{|l|}{ Heroin } \\
\hline Years of use & $13.20(6.29)$ \\
\hline Age of first use ${ }^{b}$ & $20.39(4.30)$ \\
\hline \multicolumn{2}{|l|}{ Main route of administration } \\
\hline Intravenous injection & $55 \%$ \\
\hline Inhalation (smoked) & $35 \%$ \\
\hline Insufflation (snorted) & $10 \%$ \\
\hline \multicolumn{2}{|l|}{ Cocaine } \\
\hline Years of use & $15.25(5.74)$ \\
\hline Age of first use ${ }^{b}$ & $18.83(6.86)$ \\
\hline \multicolumn{2}{|l|}{ Main route of administration } \\
\hline Intravenous injection & $35 \%$ \\
\hline Inhalation (smoked) & $10 \%$ \\
\hline Insufflation (snorted) & $55 \%$ \\
\hline \multicolumn{2}{|l|}{ Prescan drug-positive ${ }^{c}$} \\
\hline Methadone & $90 \%$ \\
\hline Morphine/opiates & $65 \%$ \\
\hline THC & $55 \%$ \\
\hline Benzodiazepines & $20 \%$ \\
\hline Cocaine & $20 \%$ \\
\hline Barbiturates & $0 \%$ \\
\hline Amphetamine & $0 \%$ \\
\hline Methamphetamine & $0 \%$ \\
\hline Training imagery questionnaires $^{a}$ & $\%$ participants with $>50 \%$ of maximum score \\
\hline VVIQ & $90 \%$ \\
\hline VMIQ & $90 \%$ \\
\hline TVIC & $95 \%$ \\
\hline IIES: Positive emotional states & $90 \%$ \\
\hline IIES: Negative emotional states & $90 \%$ \\
\hline
\end{tabular}

${ }^{a}$ VVIQ, Vividness of Visual Imagery Questionnaire; VMIQ, Vividness of Movements Imagery Questionnaire; TVIC, Test of Visual Imagery Control; IIES; Imagery Induction of Emotional States (adapted version).

${ }^{b}$ Two missing data.

'One missing data.

image; (2) the description of the scenario to be imagined, that is, one of two settings: the participant's own home ("home" condition) and the participant's habitual club ("outside-the-home" condition); and (3) the instruction to imagine oneself engaging in heroin or cocaine use (at home or outside the home) "as if" it were really happening.
Table 3. fMRI imagery scripts

\begin{tabular}{|c|c|}
\hline At home & Outside the home \\
\hline \multicolumn{2}{|l|}{ Baseline imagery } \\
\hline $\begin{array}{l}\text { 1) Imagine as vividly as possible } \\
\text { that you are at home. }\end{array}$ & $\begin{array}{l}\text { 1) Imagine as vividly as possible that } \\
\text { you are in a club. }\end{array}$ \\
\hline 2) Imagine you are relaxing at home. & 2) Imagine you are relaxing in the club \\
\hline \multicolumn{2}{|l|}{ Drug imagery } \\
\hline $\begin{array}{l}\text { 1) Imagine as vividly as possible } \\
\text { that you are at home. }\end{array}$ & $\begin{array}{l}\text { 1) Imagine as vividly as possible that } \\
\text { you are in a club. }\end{array}$ \\
\hline 2) Imagine using heroin at home. & 2) Imagine using heroin in the club. \\
\hline or & or \\
\hline $\begin{array}{l}\text { 1) Imagine as vividly as possible } \\
\text { that you are at home. }\end{array}$ & $\begin{array}{l}\text { 1) Imagine as vividly as possible that } \\
\text { you are in a club. }\end{array}$ \\
\hline 2) Imagine using cocaine at home. & 2) Imagine using cocaine in the club. \\
\hline
\end{tabular}

Thus, we created two scripts for the baseline imagery task, in which participants were asked to visualize themselves relaxing at home or in their usual club, and four scripts for the drug imagery task, one script for each combination of drug and setting: (1) cocaine at home, (2) cocaine outside the home, (3) heroin at home, and (4) heroin outside the home. The scripts did not include any information specific to the individual; that is, the scripts had a standard format that was applicable to all participants (Table 3). The scripts were then recorded and played during the imagery tasks.

Training. A week before the fMRI session, the participants underwent an imagery training session conducted in a quiet room at Villa Maraini. The main aim of the session was to familiarize the participants with the imagery procedure while listening to a recording of the scanner noise through headphones and to enhance the participants' emotional involvement during testing. Indeed, previous studies have shown that imagery training can increase the emotional response during the imagery task (Miller et al., 1987; Sinha, 2009).

The participants were asked to complete the following imagery questionnaires (adapted to Italian by Antonietti and Crespi, unpublished manuscript): (1) Vividness of Visual Imagery Questionnaire (Marks, 1989), in which the participants were instructed to visualize themselves in standard environmental contexts; (2) Vividness of Movements Imagery Questionnaire (Isaac et al., 1986), in which participants were instructed to visualize themselves while performing specific movements; (3) Test of Visual Imagery Control (Gordon, 1949), in which the participants were instructed to operate a transformation on a mental image; and (4) an adaptation of the Questionnaire on Imagery Induction of Emotional State (Wright and Mischel, 1982), in which participants were instructed to imagine situations associated with a "positive" emotional state (serene, happy, surprised and relaxed) or to a "negative" emotional state (hungry, fearful, disgusted, sad). The participants were instructed to close their eyes, to ignore as far as possible the noise of the scanner, to create a mental scenario for each condition (based on hypothetical or real events from their personal life), to imagine "living" this scenario, and finally to rate the vividness of the imagery by assigning a score from 1 (not 
clear at all) to 5 (perfectly clear) to each item in the questionnaires. The imagery training session lasted $\sim 40 \mathrm{~min}$.

Emotional imagery during the fMRI session. On the day of the fMRI scan, participants underwent a urine drug screen for amphetamine, barbiturates, benzodiazepines, cocaine, methadone, morphine/opiates, methamphetamine, and THC (Drug-Screen Multi 8TC test; nal von minden) at the Substance Misuse Service Villa Maraini (Table 2). They were then transferred to the Brain Imaging facility of the Santa Lucia Foundation. Sixteen participants took their usual dose of methadone before leaving the clinic. Smokers were allowed to smoke before the scan. All the participants were blind to the content of the experimental session.

Before entering the fMRI scanner, the participants received the following instructions by the experimenter:

"You will be asked to imagine yourself in two different settings, specifically to be either at your own home or in your usual club. Your task will be to visualize as vividly as possible the setting in your mind and to focus intensely on this situation as if it were really happening at that moment. You will then be asked to imagine using heroin or cocaine (but not heroin and cocaine combined, that is, no 'speedball') in that very same setting. You should try to focus on the effects produced by the drug while in that specific setting.

When asked to imagine being at home, it is really important that it is your own home. You can imagine being in any part of your home (living room, bedroom, bathroom, kitchen) where you usually take or have taken the drug. If you have never taken that drug in that setting, try to imagine how it would actually be to do so. The imagined event should take place in the evening, at 21:00 h."

When asked to imagine being in a club, it is really important that it is, or has been, your usual club. You can imagine being in any part of the club where you usually take or have taken the drug. If you have never taken that drug in that setting, try to imagine how it would be to actually do so. The imagined event should take place in the evening, at 21:00 h.

\section{fMRI session}

The study design is outlined in Figure 2A. During the fMRI session, each participant underwent a total of eight trials, two for each combination of drug and setting (i.e., heroin at home, cocaine at home, heroin outside, cocaine outside), in a pseudorandom sequence, counterbalanced across subjects. Subjects were equipped with headphones, and each scan was preceded by audio and video instructions guiding them through the imagery task.

Each trial began with a $60 \mathrm{~s}$ baseline period, during which the participants were first asked to imagine relaxing either at home or outside the home. Following this period, the participants were asked to imagine taking heroin or cocaine at home or in a club for $120 \mathrm{~s}$. This period was then followed by a $60 \mathrm{~s}$ rest period in which the participants were asked to stop the imagery. Immediately after the end of each trial, the participants rated the vividness of the imagery on using a visual analog scale (VAS) ranging from 1 ("not vivid at all") to 10 ("perfectly vivid") displayed on a screen, using a push button controller. The graph in Figure $2 B$ depicts the vividness

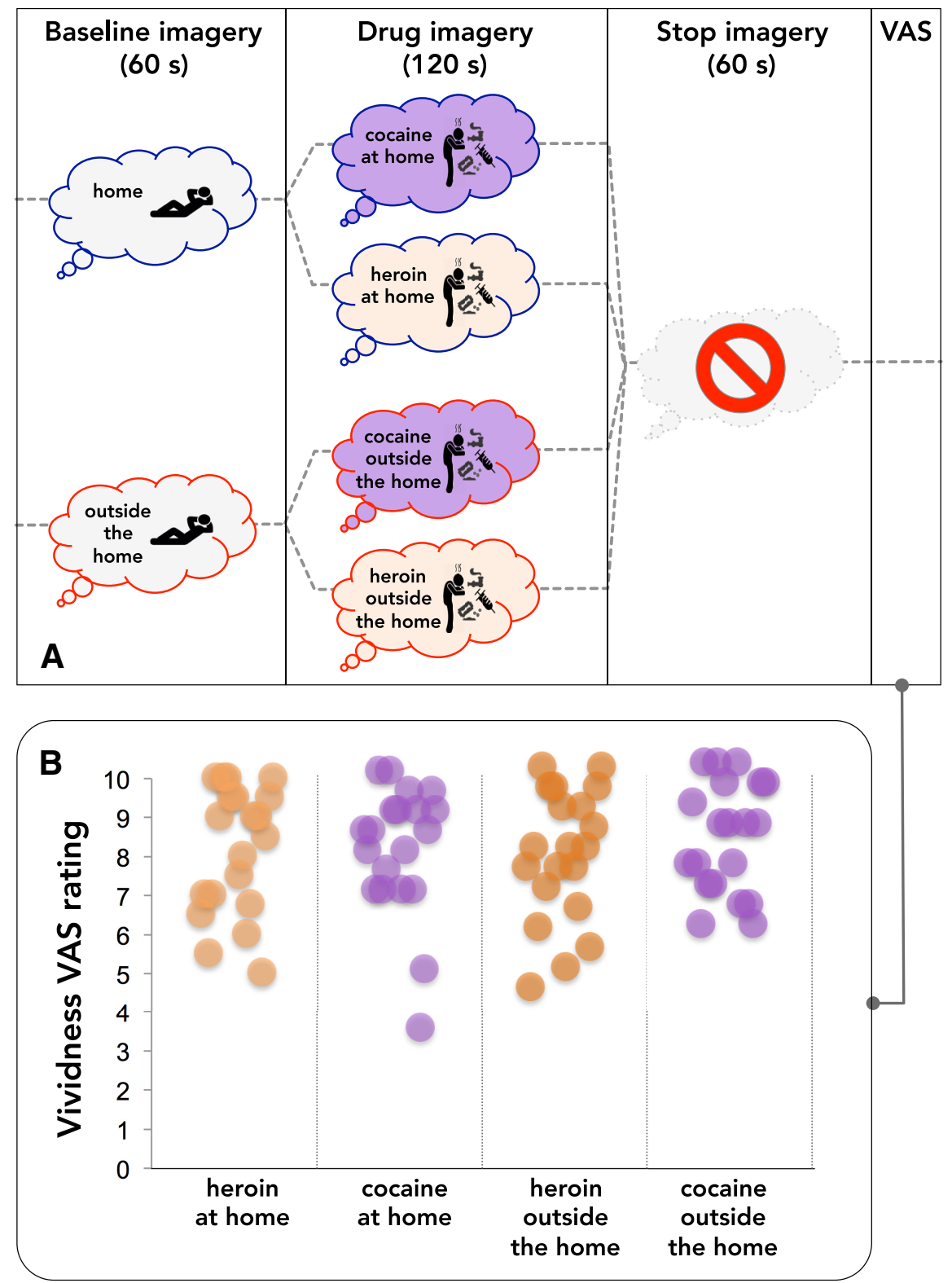

Figure 2. Outline of the imagery task during $\mathrm{fMRl}$ and vividness ratings. $A$, Outline of the 8 imagery trials during $\mathrm{fMRI}(2 \mathrm{for}$ each (t) $120 \mathrm{~s}$ (drug imagery). This period was followed by $60 \mathrm{~s}$ of rest, during which the participants were asked not to engage in imagery. Finally, the participants were asked to rate the vividness of the imagery on a VAS (1-10 points), by pressing a button. Immediately after completing the VAS, the next trial began. $\boldsymbol{B}$, Vividness ratings for individual participants.

rating from each participant after the imagery period showing no significant differences between the four combinations of drug and setting.

\section{Apparatus and image acquisition}

fMRI scans sensitive to BOLD contrast were collected using a 3.0 tesla Allegra scanner (Siemens Medical Systems) operating at the Neuroimaging Laboratory, Foundation Santa Lucia. Stimuli were generated by a control computer located outside the MR room, running an in-house software implemented in MATLAB (Galati et al., 2008; Sulpizio et al., 2013; Boccia et al., 2015). Instructions were presented simultaneously in audio and video modalities. An LCD video was used to project instructions to a back projector screen mounted inside the MR tube and visible through a mirror located inside the head coil. Presentation timing was synchronized by the acquisition of fMRI images. Responses were given through push button connected to the computer by optic fibers. Head movements were minimized by mild restraint and cushioning. 
Table 4. Brain activation during drug imagery ${ }^{a}$

\begin{tabular}{|c|c|c|c|c|c|c|c|}
\hline Cluster & Anatomical region & Extent (voxels) & $x$ & $y$ & $z$ & Peak $F$ & PeakZ \\
\hline 1 & Left mid frontal gyrus (BA8) & 7 & -24 & 17 & 64 & 13.44 & 5.45 \\
\hline 2 & Left mid frontal gyrus (BA46) & 4 & -33 & 56 & 19 & 11.24 & 4.98 \\
\hline \multirow[t]{4}{*}{3} & Left BA6, BA44, BA45 & 171 & -51 & 26 & 25 & 17.64 & 6.20 \\
\hline & Left mid frontal gyrus (BA44) & 69 & -39 & 11 & 34 & & \\
\hline & Left precentral gyrus (BA6) & 14 & -36 & 2 & 61 & & \\
\hline & Left inferior frontal gyrus (BA45) & 88 & -51 & 26 & 25 & & \\
\hline 4 & Left inferior frontal gyrus (BA45) & 17 & -48 & 44 & 7 & 14.14 & 5.59 \\
\hline 5 & Left supplementary motor area (BA32) & 8 & -6 & 20 & 46 & 12.07 & 5.16 \\
\hline 6 & Left posterior cingulum & 24 & -3 & -34 & 31 & 15.01 & 5.75 \\
\hline 7 & Left inferior parietal lobe (BA40) & 170 & -36 & -58 & 40 & 16.60 & 6.30 \\
\hline 8 & Left angular gyrus & 19 & -57 & -46 & 28 & 12.81 & 5.32 \\
\hline 9 & Left precuneus (BA7) & 19 & -9 & -67 & 43 & 14.99 & 5.75 \\
\hline 10 & Left mid temporal gyrus (BA21) posterior & 28 & -63 & -43 & -5 & 17.85 & 6.23 \\
\hline 11 & Left mid temporal gyrus (BA21) anterior & 70 & -60 & -13 & -11 & 14.71 & 5.70 \\
\hline 12 & Right mid temporal gyrus (BA21) anterior & 194 & 51 & -25 & -8 & 26.27 & 7.34 \\
\hline \multirow[t]{5}{*}{13} & Left/right caudate/thalamus & 245 & 0 & -10 & 10 & 16.51 & 6.02 \\
\hline & Left caudate & 62 & -18 & 5 & 19 & & \\
\hline & Left thalamus & 64 & -3 & -10 & 10 & & \\
\hline & Right caudate & 38 & 18 & 5 & 16 & & \\
\hline & Right thalamus & 52 & 3 & -7 & 7 & & \\
\hline 14 & Left cerebellum (crus I/II) & 118 & -36 & -61 & -32 & 17.85 & 6.23 \\
\hline 15 & Right cerebellum (crus I/II) & 224 & 15 & -79 & -35 & 20.23 & 6.59 \\
\hline 16 & Left brainstem & 11 & -3 & -28 & -14 & 13.77 & 5.52 \\
\hline 17 & Right brainstem & 7 & 15 & -25 & -11 & 12.23 & 5.20 \\
\hline
\end{tabular}

${ }^{a}$ Whole-brain analysis revealed significant activation during drug imagery (relative to baseline imagery), for at least one of the four drug-setting conditions, in the clusters listed ( $P_{\mathrm{FWE}}<0.05$ at the voxel level). Post hoc analyses indicated significant drug $\times$ setting $\times$ time interaction in the regions in bold.

fMRI images were acquired for the entire brain using a gradient EPI sequence covering the whole brain ( 34 slices, in-plane resolution $=3 \times$ $3 \mathrm{~mm}$, slice thickness $=3 \mathrm{~mm}$, interslice distance $=1.25 \mathrm{~mm}$, TR $=2210$ $\mathrm{ms}, \mathrm{TE}=30 \mathrm{~ms}$, flip angle $=70^{\circ}$ ). For each scan, a total of $113 \mathrm{fMRI}$ volumes were acquired. A high-resolution 3D T1-weighted MRI scan was acquired for each subject using an MP-RAGE sequence (Siemens, 176 slices, in-plane resolution $=0.5 \mathrm{~mm}$, in-plane resolution $=0.5 \times 0.5 \mathrm{~mm}$, slice thickness $=1 \mathrm{~mm}, \mathrm{TR}=2000 \mathrm{~ms}, \mathrm{TE}=4.38 \mathrm{~ms}$, flip angle $=8^{\circ}$ ).

\section{Data analysis}

Image analyses were performed using SPM8 (Wellcome Department of Cognitive Neurology, London; http://www.fil.ion.ucl.ac.uk/spm) implemented in MATLAB version 2011a (The MathWorks). The first four volumes of each scan were discarded to allow for T1 equilibration effects.

Functional time series from each subject were temporally corrected for slice timing, using the middle volume in time as a reference, and then spatially corrected for head movement (realigned), using a least-squares approach and a six-parameter rigid-body spatial transformation. The images were then coregistered onto their T1 image and spatially normalized using an automatic nonlinear stereotaxic normalization procedure (final voxel size: $3 \times 3 \times 3 \mathrm{~mm}$ ) and spatially smoothed with a 3D Gaussian filter ( $6 \mathrm{~mm}$ FWHM). The template image for spatial normalization into a standard stereotaxic space was based on MNI-152 template and conforms to a standard coordinate referencing system (Talairach and Tournoux, 1988).

Images were analyzed using a standard random-effect procedure. The time series of functional MR images obtained from each participant were analyzed separately. The effect of the experimental paradigm was estimated on a voxel by voxel basis, according to the GLM extended to allow the analysis of fMRI data as a time series. The model included a temporal high-pass filter to remove low-frequency confounds with a period $>128$ s. Serial correlations in the fMRI time series were estimated with a restricted maximum likelihood algorithm assuming the same correlation structure for each voxel, within each scan. The restricted maximum likelihood estimates were then used to whiten the data.

Initially, neural activation during the imagery task was modeled as a boxcar function spanning the whole duration of the imagery period and convolved with a canonical HRF, chosen to represent the relationship between neuronal activation and blood oxygenation (Friston et al., 1998). Im- ages of subject-specific parameter estimates, which represented activation relative to the baseline, were calculated for each of the four drug imagery scenarios. Intertrial resting periods were excluded from data analysis due to the potential carryover effects of the imagery task.

Using an "omnibus" F contrast, we searched for voxels exhibiting a significant increase in BOLD signal during drug imagery (relative to baseline imagery) in any of the four imagery conditions (i.e., regardless of the specific drug-setting combination). The resulting statistical parametric map was corrected for multiple comparisons based on family-wise error rate (FWE) and thresholded at $p=0.05$ corrected at voxel level (Table 4; Fig. 3).

These initial whole-brain analyses aimed at selecting a map of regions implicated in the drug imagery task. This activation map was then used as a search mask within which to look at modulations induced by drug and setting. We applied a deconvolution approach to the regionally averaged time courses from each region. We modeled each trial as a set of 12 finite impulse response basis functions (Burock and Dale, 2000; Ollinger et al., 2001) spanning $10 \mathrm{~s}$ each, starting from the onset of the imagery task. Such an approach allows for a flexible HRF modeling without any assumption on the shape of the HRF in the time period within each trial where the difference in the signal arose, although remaining in the GLM framework (Steffener et al., 2010). To directly examine the interactions relevant to our experimental questions, the resulting regional hemodynamic responses were analyzed using a three-way ANOVA with repeated measures on the factors drug (2 levels: heroin vs cocaine), setting (2 levels: home vs outside the home), and time (12 levels). Bonferroni's correction $\left[p^{\prime}=1-(1-p)^{1 / 22}\right]$ was applied to the resulting $p$ values. Effect size was estimated by calculating partial $\eta$ squared $\left(\eta_{\mathrm{p}}^{2}\right)$ values.

\section{Results}

\section{Experiment 1}

As illustrated in Figure 4, the affective valence of the drug experience changed as a function of both drug and setting. When heroin was taken at home, the majority of participants reported experiencing a pleasant affective state $(89.1 \%)$ or a mixed (both pleasant and unpleasant) state $(4.3 \%)$, whereas only $6.5 \%$ reported an unpleasant state. In contrast, when heroin was used outside the home, only $50 \%$ of participants reported positive $(39.1 \%)$ or 
mixed $(10.9 \%)$ affective states, whereas the other $50 \%$ reported an unpleasant experience. The opposite pattern was observed for cocaine. Cocaine at home produced a pleasurable state only in $26.9 \%$ of participants, whereas $61.5 \%$ experienced an unpleasant state and $11.6 \%$ a mixed state. In contrast, when taken outside the home cocaine produced pleasant or mixed states in the majority of participants $(50 \%$ and $17.3 \%$, respectively), whereas $32.7 \%$ experienced an unpleasant state.

Within-subject analysis of the data confirmed the main prediction of our working hypothesis. Indeed, the valence of the affective states induced by heroin and cocaine underwent opposite shifts as a function of setting in a sizeable number of participants. In the case of heroin, McNemar's test indicated that the valence was more negative outside the home than at home in 26 participants, whereas the opposite shift was observed only in 1 participants $(\mathrm{OR}=26$; 95\% CI $=3.53-191.6$; $p<0.0001)$. In the case of cocaine, the valence was more negative at home than outside the home in 24 participants, whereas the opposite shift was observed only in 6 participants $(\mathrm{OR}=4 ; 95 \% \mathrm{CI}=$ 1.63-9.79; $p=0.0014$ ).

As the working hypothesis further specified that the shift in valence was the result of a mismatch between exteroceptive and interoceptive information, the data were reanalyzed, including only the cases in which there was concordance for the vertical dimension (arousal in the case of cocaine, and sedation in the case of heroin). Also, this subset of data was consistent with the working hypothesis: the McNemar's test indicated opposite shifts in valence, as a function of setting, for heroin $(\mathrm{OR}=6$; $95 \% \mathrm{CI}=$ $1.78-20.37 ; p<0.001)$ and cocaine ( $\mathrm{OR}=$ infinity; $p=0.0015)$.

A secondary aim of the study concerned the assumption (often, albeit surreptitiously, incorporated in theoretical and experimental frameworks) that all addictive drugs produce a state of "pleasure." The Kolmogorov-Smirnov test indicated that the observed frequencies were not significantly different $(p>0.2)$ from those expected on the basis of either the strong or the weak version of the "pleasure" hypothesis (see Data analysis) only when heroin was used at home. This was not the case for heroin use outside the home and for cocaine in either setting $(p<0.0001$ vs either strong or weak version of the "pleasure" hypothesis). In summary, only when heroin was used at home, the emotional state induced by the drug was rated as being overall pleasant by the majority of participants. This is not consistent with the idea that the primary reason for drug use is because drugs uniformly produce a pleasurable affective state.

\section{Experiment 2}

Overall effect of drug imagery

Table 4 lists the clusters in which whole-brain analysis indicated significant changes in the BOLD signal during drug imagery relative to baseline imagery, for any of the four conditions (i.e., regardless of drug type and setting). Drug imagery produced significant activation in the left PFC (Broadman area [BA] 6, BA8,
BA44, BA45, and BA46), left supplementary motor area (BA32), left angular gyrus, left posterior cingulum, and left precuneus. Bilateral activation was evident in the caudate, thalamus, brainstem, inferior temporal gyrus, and cerebellum.

\section{Modulatory effect of setting on drug imagery}

When the data from the regions activated by drug imagery (Table 4) were again analyzed for time-dependent interaction of drug and setting in BOLD signal amplitude, we found significant drug $\times$ setting $\times$ time interaction in the middle frontal gyrus of the left PFC (BA44; Fig. 5, middle), in the left caudate (Fig. 6, left), and bilaterally in crus I/II of the cerebellum (Fig. 6, middle, right). The results of the statistical analysis are detailed in Table 5. In all these regions, the change in BOLD signal was greater when the participants were asked to imagine taking heroin outside the home and cocaine at home (the less preferred settings), compared with heroin at home and cocaine outside the home (the preferred settings). Indeed, it appears that the divergence in druginduced BOLD signal, as a function of setting, became progressively larger during the drug imagery task (Figs. 5, 6), probably because of a progressively greater emotional involvement of the participants. Most important, the $\eta_{\mathrm{p}}^{2}$ values indicated a large effect size (Cohen, 1988) for both drug $\times$ setting and drug $X$ setting $\times$ time interaction in these regions. No main effect of drug or setting was found in these regions (all Bonferroni's corrected $p$ values $>0.99$ ).

Drug $\times$ setting $\times$ time interaction was also found in smaller clusters in the left middle frontal gyrus (BA8 and BA46; Fig. 5, left, right), left precuneus, left temporal cortex, and right brainstem, even though it did not survive Bonferroni's correction (all $p$ values $\geq 0.3$ ). 


\section{A Heroin at home}

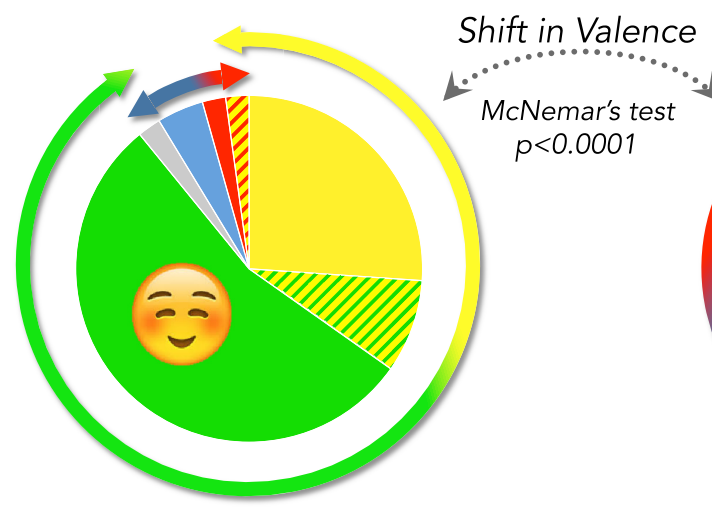

C Cocaine at home (mismatch)

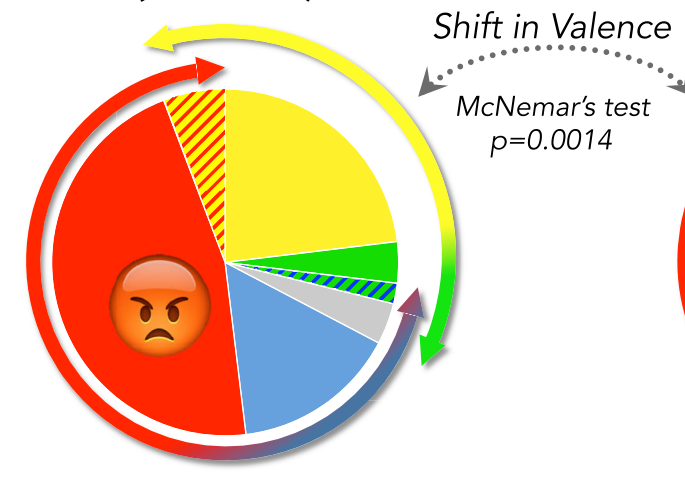

D Cocaine outside the home

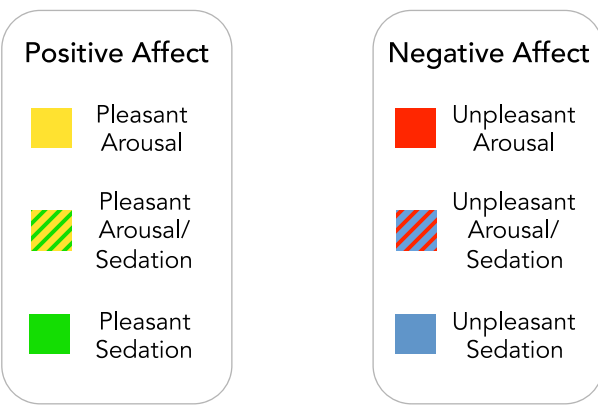

\section{B Heroin outside the home (mismatch)}
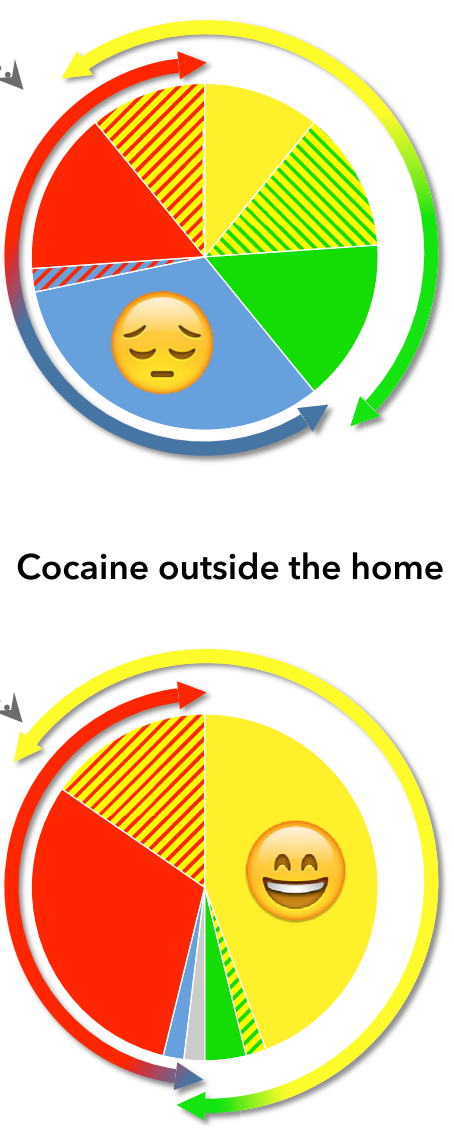

Figure 4. Subjective appraisal of the emotional valence of drug experience as a function of drug and setting. Pie charts represent the proportion of participants reporting the affective states detailed in the legend and illustrated in Figure $1 B$ after heroin $(\boldsymbol{A}, \boldsymbol{B})$ or cocaine $(\boldsymbol{C}, \boldsymbol{D})$ use. The McNemar's test indicated significant shifts in valence as a function of the setting of drug use. A small proportion of participants reported two affective states (hatched lines) or more (gray).

\section{Imagery vividness}

As shown in Figure $2 B$, the subjective vividness of drug imagery was virtually identical for heroin at home $(8.17 \pm 0.29)$, heroin outside the home $(7.80 \pm 0.27)$, cocaine at home $(8.02 \pm 0.27)$, and cocaine outside the home $(8.15 \pm 0.23)$, as confirmed by the Friedman's test $\left(\chi^{2}=3.30, p=0.3\right)$.

\section{Discussion}

We report here two major findings. First, we found that the valence of the affective state produced by heroin and cocaine in individuals with SUD shifts in opposite directions by changing the setting of drug use, heroin being experienced as more pleasant at home than outside the home, and vice versa for cocaine. Second, when an independent sample of individuals with SUD was asked to imagine typical drug-taking experiences, a double dissociation, as a function of drug and setting, in BOLD signal was observed in the dorsolateral PFC, dorsal caudate, and cerebellum.

\section{Drug, setting, and affect}

On the basis of earlier findings in humans and rats (Caprioli et al., 2007a,b, 2008, 2009; De Luca and Badiani, 2011; Testa et al., 2011; De Luca et al., 2012; Badiani and Spagnolo, 2013), it was proposed that, in the presence of a mismatch between exteroceptive information (setting) and interoceptive information generated by central and peripheral drug actions, the affective valence of drug experience would be more negative than in conditions in which there was no such a mismatch (Badiani, 2013). A particular instance of this theory is represented by the arousal state mismatch hypothesis. To test this hypothesis, we identified two scenarios in which such a mismatch should occur. In one scenario (cocaine at home), the state of arousal produced by cocaine would be at odds with a presumably quiet and safe domestic setting (but not with exciting nondomestic settings). In another scenario (heroin outside the home), the sedative effects of heroin would be at odds with exciting, potentially dangerous nonhome settings (but not in a domestic setting).

Consistent with the arousal state mismatch hypothesis, we found that the affective state produced by heroin was appraised as more pleasant when the drug was used at home than when it was when used outside the home, whereas the affective state produced by cocaine was rated as more pleasant when the drug was used outside the home then when used at home. More specifically, our data confirmed that the shift in the affective valence of heroin occurred in combination with its sedative effects, whereas the shift in the affective valence of cocaine occurred in association with its arousing effects (Fig. 4).

As discussed in the Introduction, it is reasonable to assume that the sympathomimetic effects of cocaine and the parasympathomimetic-like effect of heroin contributed to generate the respective state of emotional arousal and sedation illustrated in Figure 4 (Kreibig, 2010; Levenson, 2014). Indeed, individuals with SUD report that, under the influence of cocaine, they experience a surge in heart rate, respiratory rate, and muscular tension, as well as a decrease in salivation, whereas when under the influence of heroin, the same individuals experience a reduction in heart rate and respiratory rate (De Pirro and Badiani, manuscript in preparation).

The finding that even prototypical addictive drugs, such as heroin and cocaine, do not necessarily produce a pleasurable 


\section{Left Prefrontal Cortex (middle frontal gyrus)}
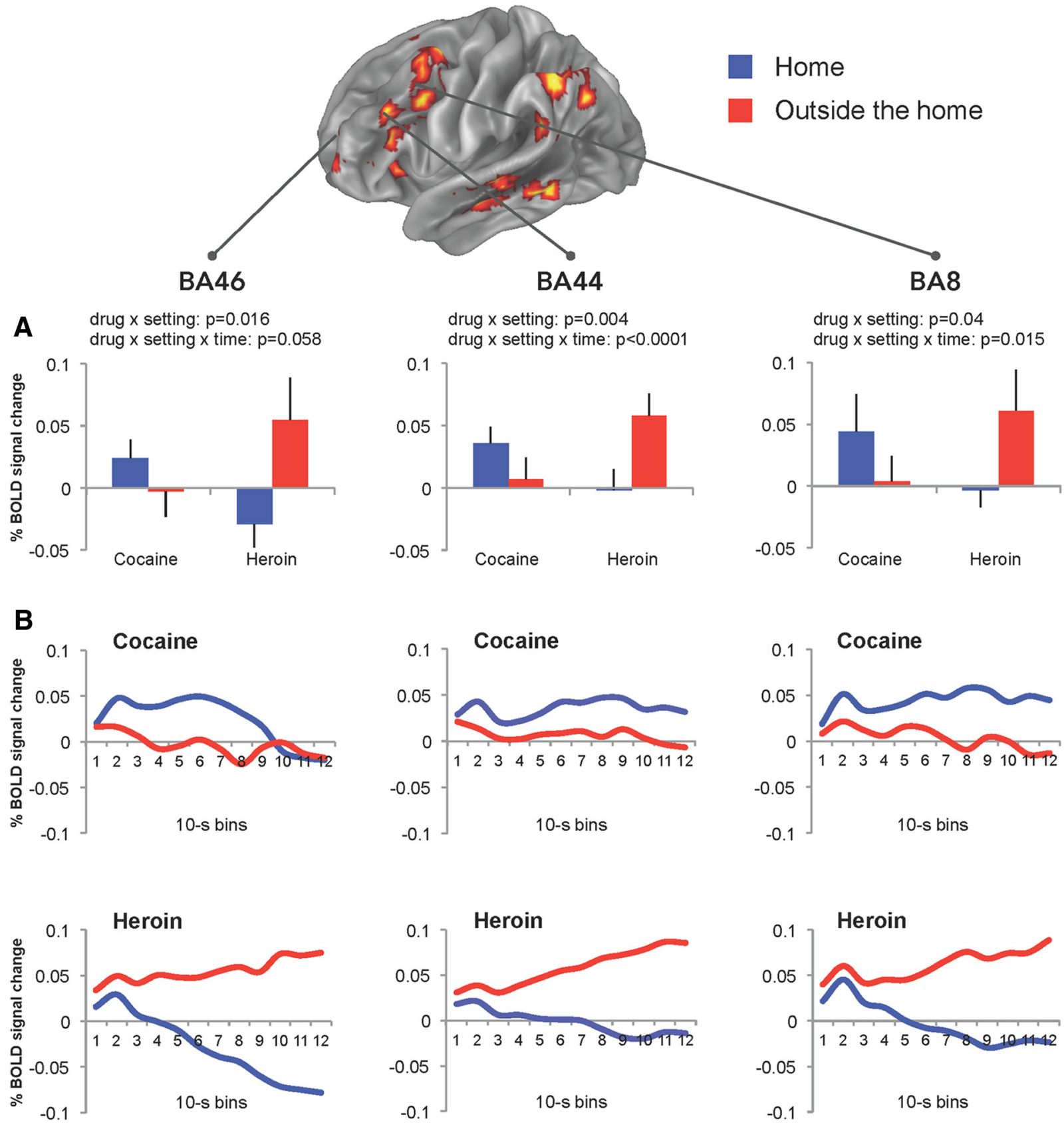

Figure 5. BOLD signal changes in the left PFC. Mean ( \pm SEM) BOLD signal changes $(\boldsymbol{A})$ during the drug imagery task (relative to baseline imagery) in the BA46, BA44, and BA8 obtained by averaging the values of $1210 \mathrm{~s}$ bins calculated using finite impulse response analysis $(\boldsymbol{B})$. The whole-brain map is the same shown in Figure 3 .

affective state in all contexts is consistent with the theory that the mechanisms underlying the motivation to use drugs are separable from those implicated in generating drug "pleasure" (Robinson and Berridge, 2008; Berridge and Kringelbach, 2013). Actually, in certain settings, almost two-thirds of experienced drug users reported that cocaine produced a mainly unpleasant affective state. This was not entirely surprising, as it has been reported previously that cocaine induces mixed (partly aversive) motivational or affective states in both rodents (Geist and Ettenberg, 1997; Ettenberg et al., 1999; Knackstedt et al., 2002) and humans (Anthony et al., 1989; Geracioti and Post, 1991; Breiter et al., 1997).

\section{Drug/setting imagery and fMRI}

Whole-brain analysis of BOLD signal changes during drug imagery indicated activation in several brain regions, including regions that have been previously implicated in the retrieval of memories: the angular gyrus (Kuhl and Chun, 2014; Bonnici et al., 2016; Richter et al., 2016), in mental imagery (e.g., the precuneus) (Fletcher et al., 1995; Richter et al., 2016), and in brain reward (e.g., the PFC and the striatum) (Goldstein and Volkow, 2002, 2011; Cox et al., 2009; Volkow et al., 2012; Leyton and Vezina, 2013).

The working hypothesis predicted that the setting should alter in opposite directions the response of the PFC and the striatum to 
Caudate
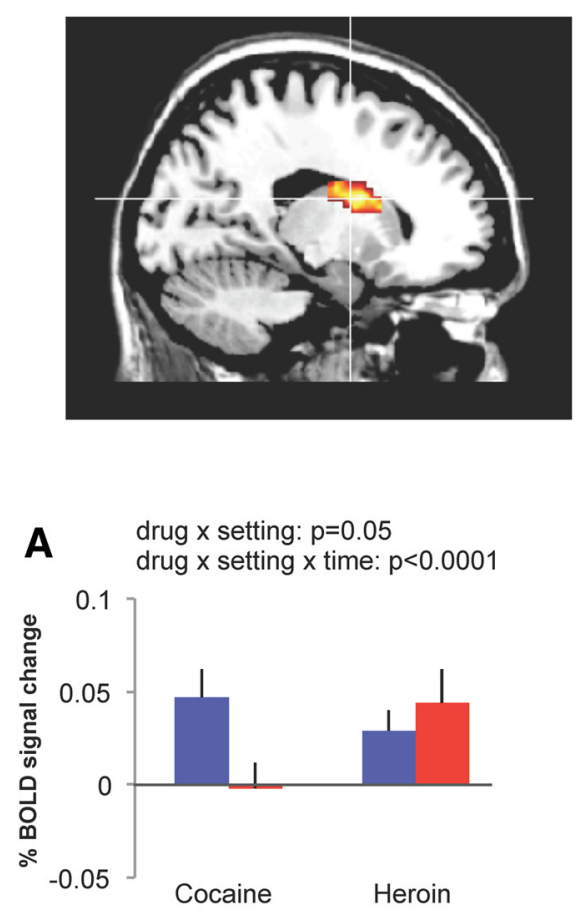

B
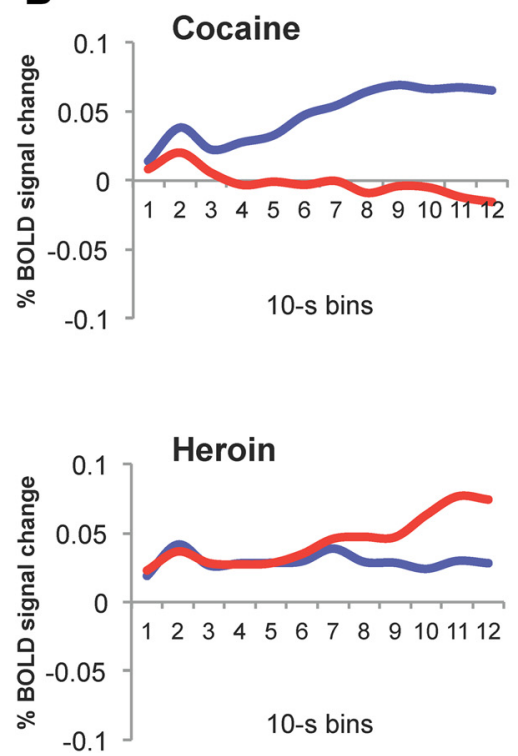

\section{Cerebellum}

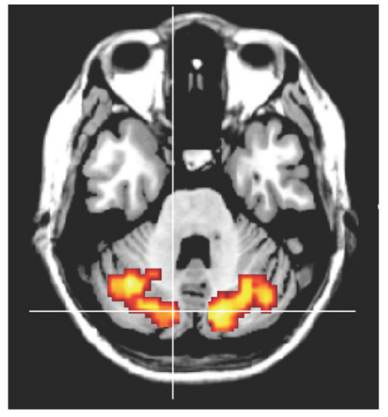

Right Crus I/II
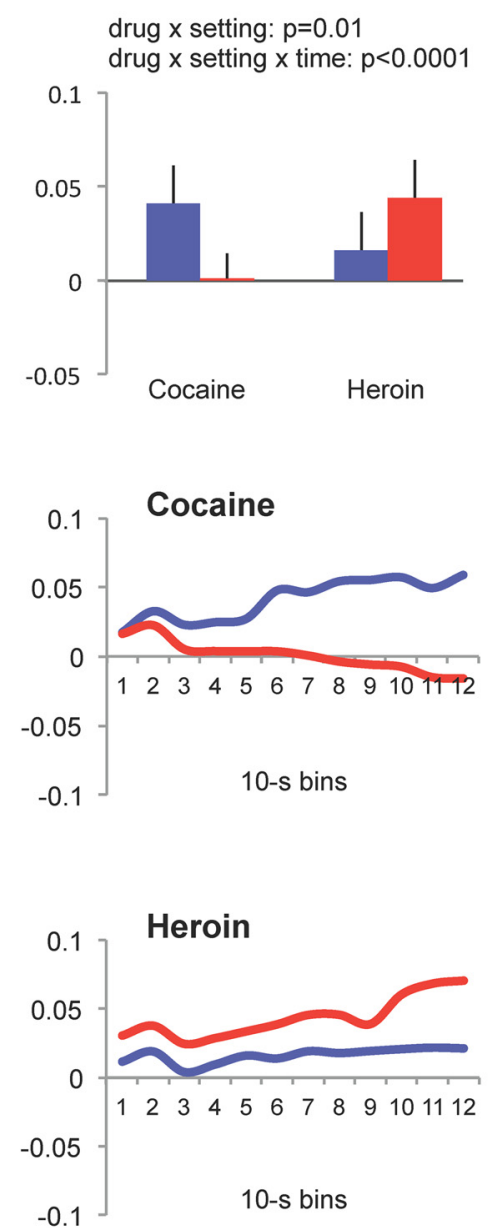

Home

Outside the home

\section{Left Crus I/II}

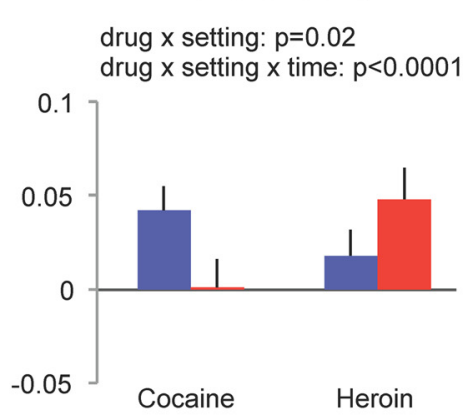

Figure 6. BOLD signal changes in the left caudate and in the cerebellum. Mean ( \pm SEM) BOLD signal changes $(\boldsymbol{A})$ during the drug imagery task (relative to baseline imagery) in the caudate and cerebellum obtained by averaging the values of 1210 s bins calculated using finite impulse response analysis $(\boldsymbol{B})$.

heroin versus cocaine imagery. The double dissociation in BOLD signal changes in these regions confirmed our prediction. Interestingly, the portion of the striatum involved in the interaction was the dorsal caudate and not the ventral striatum. Previous imaging studies in drug users have reported a selective involvement of the dorsal relative to the ventral striatum (Volkow et al., 2006; Wong et al., 2006; Boileau et al., 2007; Cox et al., 2017).

Unexpectedly, the same pattern of dissociation seen in the PFC and in the caudate was also found in the cerebellum, even though this should not have been entirely surprising given that the cerebellum is now thought to be implicated in drug addiction (for review, see Miquel et al., 2009; Moulton et al., 2014). Indeed, in the past two decades, the traditional view of the cerebellum as a primarily motor structure has been amended due to increasing evidence indicating its pivotal role in the computation of cognitive and affective processes, including the following: (1) emotional perception and encoding; (2) evaluation of emotional contexts, bodily and facial expressions, and social interactions; and (3) regulation of emotional states in relation to motor, cognitive, and contextdependent tasks (Schmahmann, 1996, 2004; Schmahmann and Sherman, 1998; Scheuerecker et al., 2007; Stoodley, 2012; Buckner, 2013; Adamaszek et al., 2014, 2017; Van Overwalle et al., 
Table 5. Brain activation during drug imagery ${ }^{a}$

\begin{tabular}{llrccc}
\hline $\begin{array}{l}\text { Anatomical } \\
\text { region }\end{array}$ & Effect/interaction & $F$ & $\begin{array}{l}p \\
\text { (uncorrected) }\end{array}$ & $\begin{array}{l}\text { (Bonferroni's } \\
\text { correction) }\end{array}$ & $\eta_{\mathrm{p}}^{2}$ \\
\hline Left BA 44 & Drug $\times$ setting & 4.879 & 0.004 & 0.08 & 0.361 \\
& Drug $\times$ setting $\times$ time & 10.719 & $<0.0001$ & $<0.01$ & 0.223 \\
Left caudate & Drug $\times$ setting & 4.208 & 0.054 & 0.70 & 0.181 \\
& Drug $\times$ setting $\times$ time & 3.918 & $<0.0001$ & $<0.01$ & 0.171 \\
Left cerebellum & Drug $\times$ setting & 6.452 & 0.020 & 0.36 & 0.254 \\
& Drug $\times$ setting $\times$ time & 3.382 & $<0.0001$ & $<0.01$ & 0.151 \\
Right cerebellum & Drug $\times$ setting & 7.907 & 0.011 & 0.22 & 0.294 \\
& Drug $\times$ setting $\times$ time & 5.812 & $<0.0001$ & $<0.01$ & 0.234
\end{tabular}

${ }^{a}$ Three-way, repeated-measures ANOVA revealed drug $\times$ setting $\left[F_{(1,19)}\right]$ and drug $\times$ setting $\times$ time $\left[F_{(11,209)}\right]$ interactions, and corresponding effect size $\left(\eta_{\mathrm{p}}^{2}\right)$, in the brain regions listed.

2015). Cerebellar-dependent behavioral and emotional disorders have been conceptualized "as either excessive or reduced responses to the external or internal environment" (Schmahmann et al., 2007). Indeed, both positive and negative emotions are thought to be processed by cerebellar circuits (Turner et al., 2007; Baumann and Mattingley, 2012). An rCBF PET study has shown that craving is associated to activation of the left posterior cerebellum (Kilts et al., 2001), and cerebellar activity in heroin users has been correlated with self-reports of negative emotions, such as "feeling tense" and "withdrawal symptoms" during cue-evoked craving (Sell et al., 2000). These findings support the idea that cerebellar activation may reflect aversive processing that is not specific to drug craving. In this respect, it is important to notice that the cerebellum is interconnected with the striatum (Hoshi et al., 2005), which is implicated in processing not only rewarding but also aversive stimuli (Ungless et al., 2004; Schultz, 2007; Leknes and Tracey, 2008), particularly the dorsal striatum (Delgado et al., 2003; Seymour et al., 2007; Gorka et al., 2017). This perspective might also help explain why the BOLD signal in the caudate, PFC, and cerebellum increased more when the participants imagined using heroin outside the home and cocaine at home (i.e., in the presence of a mismatch) than when they imagined using heroin at home and cocaine outside the home. Although the relationship between BOLD signal and underlying neural events is far from simple (Logothetis, 2008), it is possible that the fMRI data reflect the engagement of a fronto-striatal-cerebellar network in processing the negative affective state produced by a mismatch between drug effects and external environment.

Another interesting feature of our results is that the pattern of activation in most regions was lateralized to the left hemisphere, consistent with previous fMRI studies concerning memory retrieval (Spaniol et al., 2009).

In conclusion, we report here that setting of drug use exerts a substance-specific influence not only on the affective response to heroin and cocaine but also on the activity of brain regions implicated in processing drug reward and contextual information in humans, consistent with previous findings in the rat (Badiani et al., 1998, 1999; Uslaner et al., 2001a,b; Ferguson et al., 2004; Hope et al., 2006; Paolone et al., 2007; Celentano et al., 2009). The within-subject design of our study makes it especially compelling because the results cannot be ascribed to individual differences drug availability, peer influence, or other socio-demographic factors.

The procedures used in this study were based on retrospective reports and emotional imagery, given that it would have been next to impossible to administer alternatively heroin and cocaine to the same individual during the same fMRI procedure (and certainly not in real-world settings, which was our main focus of investigation). In addition, because of methodological constraints, we did not measure affective or autonomic responses to drug imagery during fMRI. To overcome these limitations, novel methodologies should be developed to elucidate the interoceptive and exteroceptive components of drug-setting interactions and dissect the exact role of relevant brain networks.

Finally, more research is necessary to verify whether the context can shape initial drug use and vulnerability to relapse in humans, as previously shown in rats (Caprioli et al., 2007b, 2008; Montanari et al., 2015). Nevertheless, by emphasizing the distinctive effects of different classes of drugs and the importance of the context of drug use (see Badiani et al., 2011), our study has potential therapeutic implications, especially for the prevention of relapse in real-world settings via Ecological Momentary Interventions (see Epstein et al., 2009).

\section{References}

Adamaszek M, D’Agata F, Kirkby KC, Trenner MU, Sehm B, Steele CJ, Berneiser J, Strecker K (2014) Impairment of emotional facial expression and prosody discrimination due to ischemic cerebellar lesions. Cerebellum 13:338-345. CrossRef Medline

Adamaszek M, D’Agata F, Ferrucci R, Habas C, Keulen S, Kirkby KC, Leggio M, Mariën P, Molinari M, Moulton E, Orsi L, Van Overwalle F, Papadelis C, Priori A, Sacchetti B, Schutter DJ, Styliadis C, Verhoeven J (2017) Consensus paper: cerebellum and emotion. Cerebellum 16:552-576. CrossRef Medline

Anthony JC, Tien AY, Petronis KR (1989) Epidemiologic evidence on cocaine use and panic attacks. Am J Epidemiol 129:543-549. CrossRef Medline

Antoniazzi RP, Sari AR, Casarin M, Moraes CM, Feldens CA (2017) Association between crack cocaine use and reduced salivary flow. Braz Oral Res 31:e42. CrossRef Medline

Avvisati R, Contu L, Stendardo E, Michetti C, Montanari C, Scattoni ML, Badiani A (2016) Ultrasonic vocalization in rats self-administering heroin and cocaine in different settings: evidence of substance-specific interactions between drug and setting. Psychopharmacology 233:1501-1511. CrossRef Medline

Badiani A (2013) Substance-specific environmental influences on drug use and drug preference in animals and humans. Curr Opin Neurobiol 23: 588-596. CrossRef Medline

Badiani A, Belin D, Epstein D, Calu D, Shaham Y (2011) Opiate versus psychostimulant addiction: the differences do matter. Nat Rev Neurosci 12: 685-700. CrossRef Medline

Badiani A, Spagnolo PA (2013) Role of environmental factors in cocaine addiction. Curr Pharm Des 19:6996-7008. CrossRef Medline

Badiani A, Oates MM, Day HE, Watson SJ, Akil H, Robinson TE (1998) Amphetamine-induced behavior, dopamine release, and c-fos mRNA expression: modulation by environmental novelty. J Neurosci 18:10579_ 10593. CrossRef Medline

Badiani A, Oates MM, Day HE, Watson SJ, Akil H, Robinson TE (1999) Environmental modulation of amphetamine-induced c-fos expression in D1 versus D2 striatal neurons. Behav Brain Res 103:203-209. CrossRef Medline

Baumann O, Mattingley JB (2012) Functional topography of primary emotion processing in the human cerebellum. Neuroimage 61:805-811. CrossRef Medline

Berger CC, Ehrsson HH (2014) The fusion of mental imagery and sensation in the temporal association cortex. J Neurosci 34:13684-13692. CrossRef Medline

Berridge KC, Kringelbach ML (2013) Neuroscience of affect: brain mechanisms of pleasure and displeasure. Curr Opin Neurobiol 23:294-303. CrossRef Medline

Billman GE (1995) Cocaine: a review of its toxic actions on cardiac function. Crit Rev Toxicol 25:113-132. CrossRef Medline

Boccia M, Piccardi L, Palermo L, Nemmi F, Sulpizio V, Galati G, Guariglia C (2015) A penny for your thoughts! Patterns of fMRI activity reveal the content and the spatial topography of visual mental images. Hum Brain Mapp 36:945-958. CrossRef Medline

Boileau I, Dagher A, Leyton M, Welfeld K, Booij L, Diksic M, Benkelfat C (2007) Conditioned dopamine release in humans: a positron emission 
tomography $\left[{ }^{11} \mathrm{C}\right]$ raclopride study with amphetamine. J Neurosci 27 : 3998-4003. CrossRef Medline

Bonnici HM, Richter FR, Yazar Y, Simons JS (2016) Multimodal feature integration in the angular gyrus during episodic and semantic retrieval. J Neurosci 36:5462-5471. CrossRef Medline

Breiter HC, Gollub RL, Weisskoff RM, Kennedy DN, Makris N, Berke JD, Goodman JM, Kantor HL, Gastfriend DR, Riorden JP, Mathew RT, Rosen BR, Hyman SE (1997) Acute effects of cocaine on human brain activity and emotion. Neuron 19:591-611. CrossRef Medline

Buckner RL (2013) The cerebellum and cognitive function: 25 years of insight from anatomy and neuroimaging. Neuron 80:807-815. CrossRef Medline

Burock MA, Dale AM (2000) Estimation and detection of event-related fMRI signals with temporally correlated noise: a statistically efficient and unbiased approach. Hum Brain Mapp 11:249-260. CrossRef Medline

Caprioli D, Celentano M, Paolone G, Badiani A (2007a) Modeling the role of environment in addiction. Prog Neuropsychopharmacol Biol Psychiatry 31:1639-1653. CrossRef Medline

Caprioli D, Paolone G, Celentano M, Testa A, Nencini P, Badiani A (2007b) Environmental modulation of cocaine self-administration in the rat. Psychopharmacology 192:397-406. CrossRef Medline

Caprioli D, Celentano M, Paolone G, Lucantonio F, Bari A, Nencini P, Badiani A (2008) Opposite environmental regulation of heroin and amphetamine self-administration in the rat. Psychopharmacology 198:395-404. CrossRef Medline

Caprioli D, Celentano M, Dubla A, Lucantonio F, Nencini P, Badiani A (2009) Ambience and drug choice: cocaine- and heroin-taking as a function of environmental context in humans and rats. Biol Psychiatry 65: 893-899. CrossRef Medline

Celentano M, Caprioli D, Dipasquale P, Di Pasquale P, Cardillo V, Nencini P, Gaetani S, Badiani A (2009) Drug context differently regulates cocaine versus heroin self-administration and cocaine- versus heroin-induced fos mRNA expression in the rat. Psychopharmacology 204:349-360. CrossRef Medline

Cichy RM, Heinzle J, Haynes JD (2012) Imagery and perception share cortical representations of content and location. Cereb Cortex 22:372-380. CrossRef Medline

Cohen J (1988) Statistical power analysis for the behavioral sciences, Ed 2. New York, NY: New York UP.

Costa VD, Lang PJ, Sabatinelli D, Versace F, Bradley MM (2010) Emotional imagery: assessing pleasure and arousal in the brain's reward circuitry. Hum Brain Mapp 31:1446-1457. CrossRef Medline

Cox SM, Benkelfat C, Dagher A, Delaney JS, Durand F, McKenzie SA, Kolivakis T, Casey KF, Leyton M (2009) Striatal dopamine responses to intranasal cocaine self-administration in humans. Biol Psychiatry 65: 846-850. CrossRef Medline

Cox SM, Yau Y, Larcher K, Durand F, Kolivakis T, Delaney JS, Dagher A, Benkelfat C, Leyton M (2017) Cocaine cue-induced dopamine release in recreational cocaine users. Sci Rep 7:46665. CrossRef Medline

Cuthbert BN, Lang PJ, Strauss C, Drobes D, Patrick CJ, Bradley MM (2003) The psychophysiology of anxiety disorder: fear memory imagery. Psychophysiology 40:407-422. CrossRef Medline

Dearing RL, Stuewig J, Tangney JP (2005) On the importance of distinguishing shame from guilt: relations to problematic alcohol and drug use. Addict Behav 30:1392-1404. CrossRef Medline

Delgado MR, Locke HM, Stenger VA, Fiez JA (2003) Dorsal striatum responses to reward and punishment: effects of valence and magnitude manipulations. Cogn Affect Behav Neurosci 3:27-38. CrossRef Medline

De Luca MT, Badiani A (2011) Ketamine self-administration in the rat: evidence for a critical role of setting. Psychopharmacology (Berl) 214:549556. CrossRef Medline

De Luca MT, Meringolo M, Spagnolo PA, Badiani A (2012) The role of setting for ketamine abuse: clinical and preclinical evidence. Rev Neurosci 23:769-780. CrossRef Medline

Dougherty DD, Shin LM, Alpert NM, Pitman RK, Orr SP, Lasko M, Macklin ML, Fischman AJ, Rauch SL (1999) Anger in healthy men: a PET study using script-driven imagery. Biol Psychiatry 46:466-472. CrossRef Medline

Epstein DH, Willner-Reid J, Vahabzadeh M, Mezghanni M, Lin JL, Preston KL (2009) Real-time electronic diary reports of cue exposure and mood in the hours before cocaine and heroin craving and use. Arch Gen Psychiatry 66:88-94. CrossRef Medline
Ettenberg A, Raven MA, Danluck DA, Necessary BD (1999) Evidence for opponent-process actions of intravenous cocaine. Pharmacol Biochem Behav 64:507-512. CrossRef Medline

Ferguson SM, Thomas MJ, Robinson TE (2004) Morphine-induced c-fos mRNA expression in striatofugal circuits: modulation by dose, environmental context, and drug history. Neuropsychopharmacology 29:16641674. CrossRef Medline

Fletcher PC, Frith CD, Baker SC, Shallice T, Frackowiak RS, Dolan RJ (1995) The mind's eye-precuneus activation in memory-related imagery. Neuroimage 2:195-200. CrossRef Medline

Friston KJ, Fletcher P, Josephs O, Holmes A, Rugg MD, Turner R (1998) Event-related fMRI: characterizing differential responses. Neuroimage 7:30-40. CrossRef Medline

Galati G, Committeri G, Spitoni G, Aprile T, Di Russo F, Pitzalis S, Pizzamiglio L (2008) A selective representation of the meaning of actions in the auditory mirror system. Neuroimage 40:1274-1286. CrossRef Medline

Geist TD, Ettenberg A (1997) Concurrent positive and negative goalbox events produce runway behaviors comparable to those of cocaine-reinforced rats. Pharmacol Biochem Behav 57:145-150. CrossRef Medline

Geracioti TD Jr, Post RM (1991) Onset of panic disorder associated with rare use of cocaine. Biol Psychiatry 29:403-406. CrossRef Medline

Goldstein RZ, Volkow ND (2002) Drug addiction and its underlying neurobiological basis: neuroimaging evidence for the involvement of the frontal cortex. Am J Psychiatry 159:1642-1652. CrossRef Medline

Goldstein RZ, Volkow ND (2011) Dysfunction of the prefrontal cortex in addiction: neuroimaging findings and clinical implications. Nat Rev Neurosci 12:652-669. CrossRef Medline

Gordon R (1949) An investigation into some of the factors that favour the formation of stereotyped images. Br J Psychol Gen Sect 39:156-167. CrossRef Medline

Gorka SM, Lieberman L, Shankman SA, Phan KL (2017) Association between neural reactivity and startle reactivity to uncertain threat in two independent samples. Psychophysiology 54:652-662. CrossRef Medline

Haddad GG, Lasala PA (1987) Effect of parasympathetic blockade on ventilatory and cardiac depression induced by opioids. Respir Physiol 67:101-114. CrossRef Medline

Hope BT, Simmons DE, Mitchell TB, Kreuter JD, Mattson BJ (2006) Cocaine-induced locomotor activity and fos expression in nucleus accumbens are sensitized for 6 months after repeated cocaine administration outside the home cage. Eur J Neurosci 24:867-875. CrossRef Medline

Hoshi E, Tremblay L, Féger J, Carras PL, Strick PL (2005) The cerebellum communicates with the basal ganglia. Nat Neurosci 8:1491-1493. CrossRef Medline

Isaac A, Marks DF, Russell DG (1986) An instrument for assessing imagery of movement: the Vividness of Movement Imagery Questionnaire (VMIQ). J Mental Imagery 10:23-30.

Kaye LK, Malone SA, Wall HJ (2017) Emojis: insights, affordances, and possibilities for psychological science. Trends Cogn Sci 21:66-68. CrossRef Medline

Kilts CD, Schweitzer JB, Quinn CK, Gross RE, Faber TL, Muhammad F, Ely TD, Hoffman JM, Drexler KP (2001) Neural activity related to drug craving in cocaine addiction. Arch Gen Psychiatry 58:334-341. CrossRef Medline

Knackstedt LA, Samimi MM, Ettenberg A (2002) Evidence for opponentprocess actions of intravenous cocaine and cocaethylene. Pharmacol Biochem Behav 72:931-936. CrossRef Medline

Kosslyn SM, Ganis G, Thompson WL (2001) Neural foundations of imagery. Nat Rev Neurosci 2:635-642. CrossRef Medline

Kreibig SD (2010) Autonomic nervous system activity in emotion: a review. Biol Psychol 84:394-421. CrossRef Medline

Kuhl BA, Chun MM (2014) Successful remembering elicits event-specific activity patterns in lateral parietal cortex. J Neurosci 34:8051-8060. CrossRef Medline

Lang PJ (1979) A bio-informational theory of emotional imagery. Psychophysiology 16:495-512. CrossRef Medline

Lang PJ, Kozak MJ, Miller GA, Levin DN, McLean A Jr (1980) Emotional imagery: conceptual structure and pattern of somato-visceral response. Psychophysiology 17:179-192. CrossRef Medline

Lee SH, Kravitz DJ, Baker CI (2012) Disentangling visual imagery and perception of real-world objects. Neuroimage 59:4064-4073. CrossRef Medline 
Leknes S, Tracey I (2008) A common neurobiology for pain and pleasure. Nat Rev Neurosci 9:314-320. CrossRef Medline

Levenson RW (2014) The autonomic nervous system and emotion. Emot Rev 6:100-112. CrossRef

Leyton M, Vezina P (2013) Striatal ups and downs: their roles in vulnerability to addictions in humans. Neurosci Biobehav Rev 37:19992014. CrossRef Medline

Logothetis NK (2008) What we can do and what we cannot do with fMRI. Nature 453:869-878. CrossRef Medline

Luoma JB, Kohlenberg BS, Hayes SC, Fletcher L (2012) Slow and steady wins the race: a randomized clinical trial of acceptance and commitment therapy targeting shame in substance use disorders. J Consult Clin Psychol 80:43-53. CrossRef Medline

Luoma JB, Nobles RH, Drake CE, Hayes SC, O’Hair A, Fletcher L, Kohlenberg BS (2013) Self-stigma in substance abuse: development of a new measure. J Psychopathol Behav Assess 35:223-234. CrossRef Medline

Maceira AM, Ripoll C, Cosin-Sales J, Igual B, Gavilan M, Salazar J, Belloch V, Pennell DJ (2014) Long term effects of cocaine on the heart assessed by cardiovascular magnetic resonance at 3T. J Cardiovasc Magn Reson 16:26. CrossRef Medline

Marks DF (1989) Construct validity of the vividness of visual imagery questionnaire. Percept Mot Skills 69:459-465. CrossRef Medline

Massey FJ (1951) The Kolmogorov-Smirnov test for goodness of fit. J Am Stat Assoc 46:68-78. CrossRef

McNemar Q (1947) Note on the sampling error of the difference between correlated proportions or percentages. Psychometrika 12:153-157. CrossRef Medline

McTeague LM, Lang PJ, Laplante MC, Cuthbert BN, Strauss CC, Bradley MM (2009) Fearful imagery in social phobia: generalization, comorbidity, and physiological reactivity. Biol Psychiatry 65:374-382. CrossRef Medline

Miller GA, Levin DN, Kozak MJ, Cook EW, McLean A, Lang PJ (1987) Individual differences in imagery and the psychophysiology of emotion. Cognition Emotion 1:367-390. CrossRef

Miquel M, Toledo R, García LI, Coria-Avila GA, Manzo J (2009) Why should we keep the cerebellum in mind when thinking about addiction? Curr Drug Abuse Rev 2:26-40. CrossRef Medline

Montanari C, Stendardo E, De Luca MT, Meringolo M, Contu L, Badiani A (2015) Differential vulnerability to relapse into heroin versus cocaineseeking as a function of setting. Psychopharmacology 232:2415-2424. CrossRef Medline

Moulton EA, Elman I, Becerra LR, Goldstein RZ, Borsook D (2014) The cerebellum and addiction: insights gained from neuroimaging research. Addict Biol 19:317-331. CrossRef Medline

Nathanson L, Rivers SE, Flynn LM, Brackett MA (2016) Creating emotionally intelligent schools with RULER. Emot Rev 8:305-310. CrossRef

Nilsson M, Poulsen JL, Brock C, Sandberg TH, Gram M, Frøkjær JB, Krogh K, Drewes AM (2016) Opioid-induced bowel dysfunction in healthy volunteers assessed with questionnaires and MRI. Eur J Gastroenterol Hepatol 28:514-524. CrossRef Medline

Ollinger JM, Shulman GL, Corbetta M (2001) Separating processes within a trial in event-related functional MRI: I. The method. Neuroimage 13: 210-217. CrossRef Medline

Owen AM, Coleman MR, Boly M, Davis MH, Laureys S, Pickard JD (2006) Detecting awareness in the vegetative state. Science 313:1402. CrossRef Medline

Paolone G, Palopoli M, Marrone MC, Nencini P, Badiani A (2004) Environmental modulation of the interoceptive effects of amphetamine in the rat. Behav Brain Res 152:149-155. CrossRef Medline

Paolone G, Conversi D, Caprioli D, Bianco PD, Nencini P, Cabib S, Badiani A (2007) Modulatory effect of environmental context and drug history on heroin-induced psychomotor activity and fos protein expression in the rat brain. Neuropsychopharmacology 32:2611-2623. CrossRef Medline

Reddy L, Tsuchiya N, Serre T (2010) Reading the mind's eye: decoding category information during mental imagery. Neuroimage 50:818-825. CrossRef Medline

Richter FR, Cooper RA, Bays PM, Simons JS (2016) Distinct neural mechanisms underlie the success, precision, and vividness of episodic memory. Elife 5:e18260. CrossRef Medline

Robinson TE, Berridge KC (2008) Review: the incentive sensitization theory of addiction: some current issues. Philos Trans R Soc Lond B Biol Sci 363:3137-3146. CrossRef Medline

Rollins M, Hampson PJ, Marks DE, Richardson JTE (1992) Mental imagery: current developments. Am J Psychol 105:146. CrossRef

Russell JA (1980) A circumplex model of affect. J Pers Soc Psychol 39:11611178. CrossRef

Russell JA, Anna W, Mendelsohn GA (1989) Affect grid: a single-item scale of pleasure and arousal. J Pers Soc Psychol 57:493-502. CrossRef

Scheuerecker J, Frodl T, Koutsouleris N, Zetzsche T, Wiesmann M, Kleemann AM, Brückmann H, Schmitt G, Möller HJ, Meisenzahl EM (2007) Cerebral differences in explicit and implicit emotional processing: an fMRI study. Neuropsychobiology 56:32-39. CrossRef Medline

Schmahmann JD (1996) From movement to thought: anatomic substrates of the cerebellar contribution to cognitive processing. Hum Brain Mapp 4:174-198. CrossRef Medline

Schmahmann JD (2004) Disorders of the cerebellum: ataxia, dysmetria of thought, and the cerebellar cognitive affective syndrome. J Neuropsychiatry Clin Neurosci 16:367-378. CrossRef Medline

Schmahmann JD, Sherman JC (1998) The cerebellar cognitive affective syndrome. Brain 121:561-579. CrossRef Medline

Schmahmann JD, Weilburg JB, Sherman JC (2007) The neuropsychiatry of the cerebellum: insights from the clinic. Cerebellum 6:254-267. CrossRef Medline

Schultz W (2007) Multiple dopamine functions at different time courses. Annu Rev Neurosci 30:259-288. CrossRef Medline

Sell LA, Morris JS, Bearn J, Frackowiak RS, Friston KJ, Dolan RJ (2000) Neural responses associated with cue evoked emotional states and heroin in opiate addicts. Drug Alcohol Depend 60:207-216. CrossRef Medline

Seymour B, Daw N, Dayan P, Singer T, Dolan R (2007) Differential encoding of losses and gains in the human striatum. J Neurosci 27:4826-4831. CrossRef Medline

Sinha R (2009) Modeling stress and drug craving in the laboratory: implications for addiction treatment development. Addict Biol 14:84-98. CrossRef Medline

Sofuoglu M, Sewell RA (2009) Norepinephrine and stimulant addiction. Addict Biol 14:119-129. CrossRef Medline

Spaniol J, Davidson PS, Kim AS, Han H, Moscovitch M, Grady CL (2009) Event-related fMRI studies of episodic encoding and retrieval: metaanalyses using activation likelihood estimation. Neuropsychologia 47: 1765-1779. CrossRef Medline

Steffener J, Tabert M, Reuben A, Stern Y (2010) Investigating hemodynamic response variability at the group level using basis functions. Neuroimage 49:2113-2122. CrossRef Medline

Stoodley CJ (2012) The cerebellum and cognition: evidence from functional imaging studies. Cerebellum 11:352-365. CrossRef Medline

Sulpizio V, Committeri G, Lambrey S, Berthoz A, Galati G (2013) Selective role of lingual/parahippocampal gyrus and retrosplenial complex in spatial memory across viewpoint changes relative to the environmental reference frame. Behav Brain Res 242:62-75. CrossRef Medline

Talairach J, Tournoux P (1988) Co-planar stereotaxic atlas of the human brain: 3-dimensional proportional system: an approach to cerebral imaging. Stuttgart, Germany: Thieme.

Testa A, Nencini P, Badiani A (2011) The role of setting in the oral selfadministration of alcohol in the rat. Psychopharmacology (Berl) 215: 749-760. CrossRef Medline

Thornhill JA, Townsend C, Gregor L (1989) Intravenous morphine infusion (IMF) to drug-naive, conscious rats evokes bradycardic, hypotensive effects, but pressor actions are elicited after IMF to rats previously given morphine. Can J Physiol Pharmacol 67:213-222. CrossRef Medline

Turner BM, Paradiso S, Marvel CL, Pierson R, Boles Ponto LL, Hichwa RD, Robinson RG (2007) The cerebellum and emotional experience. Neuropsychologia 45:1331-1341. CrossRef Medline

Ungless MA, Magill PJ, Bolam JP (2004) Uniform inhibition of dopamine neurons in the ventral tegmental area by aversive stimuli. Science 303: 2040-2042. CrossRef Medline

Uslaner J, Badiani A, Day HE, Watson SJ, Akil H, Robinson TE (2001a) Environmental context modulates the ability of cocaine and amphetamine to induce c-fos mRNA expression in the neocortex, caudate 
nucleus, and nucleus accumbens. Brain Res 920:106-116. CrossRef Medline

Uslaner J, Badiani A, Norton CS, Day HE, Watson SJ, Akil H, Robinson TE (2001b) Neurosci 13:1977-1983. CrossRef Medline

Van Overwalle F, Baetens K, Mariën P, Vandekerckhove M (2015) Cerebellar areas dedicated to social cognition? A comparison of meta-analytic and connectivity results. Soc Neurosci 10:337-344. CrossRef Medline

Volkow ND, Wang GJ, Fowler JS, Logan J, Gatley SJ, Wong C, Hitzemann R, Pappas NR (1999) Reinforcing effects of psychostimulants in humans are associated with increases in brain dopamine and occupancy of $\mathrm{D}(2)$ receptors. J Pharmacol Exp Ther 291:409-415. Medline

Volkow ND, Wang GJ, Telang F, Fowler JS, Logan J, Childress AR, Jayne M, Ma Y, Wong C (2006) Cocaine cues and dopamine in dorsal striatum: mechanism of craving in cocaine addiction. J Neurosci 26:6583-6588. CrossRef Medline

Volkow ND, Wang GJ, Fowler JS, Tomasi D (2012) Addiction circuitry in the human brain. Annu Rev Pharmacol Toxicol 52:321-336. CrossRef Medline

Wong DF, Kuwabara H, Schretlen DJ, Bonson KR, Zhou Y, Nandi A, Brasić JR, Kimes AS, Maris MA, Kumar A, Contoreggi C, Links J, Ernst M, Rousset O, Zukin S, Grace AA, Lee JS, Rohde C, Jasinski DR, Gjedde A, et al. (2006) Increased occupancy of dopamine receptors in human striatum during cue-elicited cocaine craving. Neuropsychopharmacology 31: 2716-2727. CrossRef Medline

Wright J, Mischel W (1982) Influence of affect on cognitive social learning person variables. J Pers Soc Psychol 43:901. CrossRef 